\title{
Embalagem e tratamento hidrotérmico na manutenção da qualidade pós-colheita de jambu
}

\author{
Olganeth Moreira de Oliveira ${ }^{1}$, Keren Railka Paiva Menezes ${ }^{1}$, Guilherme Celestino de Souza \\ Santos $^{1}$, Alex Guimarães Sanches ${ }^{2}$, Carlos Alberto Martins Cordeiro ${ }^{3}$ \\ ${ }^{1}$ Universidade Federal do Pará, Campus Altamira, Altamira-PA, Brasil. E-mail: olganeth2010@ hotmail.com, \\ kerenrailka@hotmail.com, guimencel@gmail.com \\ ${ }^{2}$ Universidade Federal do Ceará, Campus do Pici, Fortaleza, CE. E-mail: alexsanches.eng@ gmail.com \\ ${ }^{3}$ Universidade Federal do Pará, Campus Bragança, Bragança-PA, Brasil. E-mail: camcordeiro2006@ gmail.com
}

Recebido:18/04/2017; Aceito: 30/06/2017

\section{RESUMO}

O jambu também conhecido como agrião bravo e jambu pequeno é uma hortaliça folhosa que apresenta elevada perecibilidade após a colheita, observada pela rápida deterioração e intensa perda de água. Desta forma, o presente trabalho tem por objetivo avaliar a conservação pós-colheita do jambu pelo uso do hidroresfriamento e do acondicionamento em diferentes embalagens. $\mathrm{O}$ experimento foi conduzido em um delineamento experimental inteiramente casualizado em arranjo fatorial $5 \times 5$, sendo cinco tratamentos e cinco tempos de armazenamento com quatro repetições. A unidade experimental foi formada por amostras de $50 \mathrm{~g}$. Houve efeito significativo ao nível de $1 \%$ e $5 \%$ pelo teste $\mathrm{F}$ para todas as variáveis avaliadas tanto na interação entre os fatores dias de armazenamento e tratamentos, quanto na forma isolada. A utilização do hidroresfriamento preservou a qualidade das amostras em relação à testemunha e o efeito combinado do hidroresfriamento e embalagens plásticas promoveram maior conservação do jambu para todas as variáveis avaliadas, sobretudo nas embalagens saco plástico de polietileno e PVC, durante 9 dias de armazenamento. Recomenda-se a utilização da embalagem saco plástico de polietileno pelo potencial de conservação e preço mais acessível.

Palavras-chave: Spilanthes acmella var.oleracea L, atmosfera modificada, conservação.

\section{Packaging and hydrothermal treatment in post-harvest quality maintenance of jambu}

\begin{abstract}
The jambu also known as brave watercress and small jambu is a hardwood vegetable that presents high perishability after harvest, observed by the rapid deterioration and intense loss of water. In this way, the present work has the objective of evaluating the post-harvest conservation of the jambu by the use of hydrocooling and packaging in different packages. The experiment was conducted in a completely randomized experimental design in a $5 \times 5$ factorial arrangement, with five treatments and five storage times with four replicates and the experimental plot formed by $50 \mathrm{~g}$ samples. There was a significant effect at the $1 \%$ and $5 \%$ level by the $\mathrm{F}$ test for all variables evaluated both in the interaction between the days storage factors and treatments, and in the isolated form. The use of hydrocooling preserved the quality of the samples in relation to the control, and the combined effect of hydrocooling and plastic packaging promoted a better preservation of the jambu for all variables evaluated, especially in polyethylene and PVC plastic bags during 9 days of storage. It is recommended to use the polyethylene plastic bag packaging because of the potential conservation and the most affordable price.
\end{abstract}

Key words: Spilanthes acmella var.oleracea L, modified atmosphere, conservation 


\section{Introdução}

O jambu (Spilanthes acmella var. oleracea L.), também conhecida como agrião bravo e jambu pequeno é uma hortaliça folhosa composta por folhas simples e opostas com flores pequenas de coloração amarela reunidas em capítulos, é considerada uma planta subereta, anual e aromática chegando até $30 \mathrm{~cm}$ de altura sendo cultivada em regiões equatoriais e tropicais em locais úmidos e sombreados (LORENZI; MATOS, 2008).

É uma hortaliça muito apreciada em pratos típicos dos estados do Pará e Amazonas como o tacacá e o arroz paraense especialmente quando se utiliza as folhas e as pequenas flores amarelas causando algo como um amortecimento inebriante das mucosas (MAPA, 2010). Assim como as demais hortaliças folhosas, o jambu apresenta elevada perecibilidade após a colheita, observada pela rápida deterioração e intensa perda de água, com potencial de conservação de poucos dias, fazendo-se necessário o consumo imediato ou a doção de técnicas que prolonguem sua conservação póscolheita (GUSMÃO e GUSMÃO,2013).

Devido à elevada taxa de perdas após a colheita de hortaliças folhosas em função do elevado déficit hídrico que leva ao murchamento e recusa por parte do consumidor, torna-se necessário o desenvolvimento de técnicas de manuseio e conservação visando aumentar sua vida útil pós-colheita

Um dos métodos de armazenamento consiste no uso de embalagem para armazenagem de frutos e hortaliças; constitui uma barreira artificial para gerar a atmosfera modificada, mantendo assim a qualidade e protegendoos contra danos externos favorecidos pelas condições ambientes adversas tais como temperatura, umidade, acúmulo de gases, transporte, manuseio entre outros (CHITARRA; CHITARRA, 2005). São utilizados materiais como o polietileno, policloreto de vinila e similares (MACHADO et al., 2007).

Outra técnica de baixo custo e acessível ao consumidor é a operação de resfriamento rápido utilizada para prolongar a vida de prateleira do produto, inibir o crescimento de microrganismos patogênicos e reduzir a perda de água (FRANÇA et al., 2015). Dentre as operações de resfriamento rápido, destaca-se o hidroresfriamento que em termos práticos, consiste na imersão ou na aspersão de água gelada ou com gelo com temperatura maior do que a água empregada no processo de lavagem dos frutos e hortaliças (LUENGO; CALBO, 2011).

Nesse contexto é de fundamental importância o conhecimento do potencial de conservação das folhas de jambu para que possam ser desenvolvidas estratégias adequadas para os procedimentos de embalagem, armazenamento e comercialização dessa folhosa. Assim, o objetivo do presente trabalho consiste em avaliar os efeitos do hidroresfriamento e do acondicionamento em diferentes embalagens na manutenção da qualidade e dos atributos físicoquímicos e sensoriais das folhas de jambu durante o armazenamento refrigerado.

\section{Material e Métodos}

As folhas de jambu foram obtidas em feira livre no Município de Altamira-PA, em julho de 2016, nas primeiras horas da manhã levando-se em consideração folhas ausentes de defeitos físicos e ou acometidas por pragas e doenças. As folhas foram transportadas ao Laboratório de Tecnologia de Produtos da Universidade Federal do Pará, Campus, Altamira-PA onde se procedeu às etapas de limpeza com lavagem em água corrente para eliminação das impurezas de campo com posterior imersão em solução contendo hipoclorito de sódio a $5 \%$ por um período de 3 minutos e secas em bancadas de alvenaria em condição de temperatura ambiente.

As folhas foram divididas em lotes e então submetidas primeiramente ao tratamento com hidroresfriamento, com exceção de um lote de folhas cujo maço formado por $50 \mathrm{~g}$ foi somente amarrado com fio de nylon e acondicionado em refrigerador, caracterizando o tratamento controle.

As demais amostras que foram submetidas ao tratamento com hidroresfriamento mantiveram-se imersas em água contendo gelo na proporção de 1:3 $(\mathrm{v} / \mathrm{v})$ à temperatura de $5^{\circ} \mathrm{C}$ por um período de 5 minutos, sendo o controle da temperatura realizado com termômetro manual. Após o tempo de exposição, as folhas foram retiradas e centrifugadas para a retirada do excesso de água, pesadas em balança semi-analítica e então acondicionadas em bandejas de isopor de poliestireno expandido revestida com filme plástico de PVC 14 micras (BPE+PVC), em embalagens de polietileno tereftalato (PET) e em sacos plásticos de polietileno de baixa densidade 6 micras (SPBD). Neste processo foram formados maços de $50 \mathrm{~g}$ que só foram amarrados com fio de nylon.

$\mathrm{O}$ experimento foi conduzido em um delineamento experimental inteiramente casualizado em um arranjo fatorial $5 \times 5$, sendo cinco tipos de embalagens: controle, sem hidroresfriamento e sem embalagem; hidroresfriamento e sem embalagem; BPE+PVC, PET; SPBD e cinco dias de armazenamento/avaliação: 0, 3, 6, 9 e 12 dias com quatro repetições; a parcela experimental foi constituída por amostras de $50 \mathrm{~g}$.

As amostras foram armazenadas em refrigerador à temperatura de $10 \pm 2^{\circ} \mathrm{C}$ e $85 \pm 5 \%$ de UR por um período de 12 dias e avaliadas em intervalos de três dias sobre as seguintes variáveis físico-químicas e sensoriais: 
A qualidade sensorial das amostras sobre as variáveis: coloração, escurecimento, odor e qualidade geral (Tabela 1) foram determinadas mediante avaliação direta sobre as folhas atribuindo-se notas em uma escala hedônica de cinco pontos (5-1), conforme preconizado por Aoac (2012). A nota 3 foi considerada o limite de comercialização.

Tabela 1: Avaliação sensorial sobre os atributos coloração, escurecimento, odor e qualidade geral em folhas de jambu tratadas hidrotermicamente e armazenadas em diferentes embalagens

\begin{tabular}{ll}
\hline \multicolumn{1}{c}{ Coloração } & \multicolumn{1}{c}{ Escurecimento } \\
\hline 5. Folhas verdes & 5. Nenhum/ausente \\
4. Folhas verde claro & 4. Leve \\
3. Folhas verde amareladas & 3. Moderado \\
2. Folhas amarelo esverdeadas & $\begin{array}{l}\text { 2. Severo } \\
\text { 1. Extremo }\end{array}$ \\
1. Folhas amareladas & \multicolumn{1}{c}{ Qualidade geral } \\
\hline \multicolumn{1}{c}{ Odor } & 5. Excelente, livre de \\
\hline 5. Ausente/fraco & defeitos \\
4. Boa, pequenos defeitos \\
3. Moderado & 3. Defeitos médios, limitado \\
& para consumo \\
2. Odor característico fraco & 2. Defeitos excessivos \\
1. Odor forte podre & 1. Podre, não utilizável \\
\hline
\end{tabular}

Fonte: Aoac, 2012

A perda de massa fresca foi determinada com auxílio de uma balança semi-analítica com precisão de 0,1 g calculando-se a diferença entre a perda de peso do dia inicial e aquela realizada no dia de avaliação sendo os resultados expressos em porcentagem (\%).

O conteúdo de sólidos solúveis foi mensurado com auxílio de refratômetro a partir da maceração de $10 \mathrm{~g}$ da amostra e utilizando-se uma gota do liquido sobrenadante no prisma do aparelho conforme Aoac (2012) e os resultados expressos em ${ }^{\circ}$ Brix.

A acidez total foi determinada por titulação com $\mathrm{NaOH}$ 0,1 M de solução e $1 \%$ do indicador fenolftaleína através da homogeneização de $10 \mathrm{~g}$ da folha macerada em água destilada sendo os resultados expressos em g/100g de ácido oxálico.

Os resultados de cada análise foram submetidos à análise de variância e a comparação das médias pelo teste de Tukey ao nível de 5\% de probabilidade através da interface do software ASSISTAT 7.7 versão beta (SILVA e AZEVEDO, 2016)

\section{Resultados e Discussão}

Analisando a Tabela 2 observa-se que houve efeito significativo ao nível de $1 \%$ de probabilidade para todas as variáveis avaliadas quanto ao efeito isolado dos fatores embalagens e dias.

A perda de massa em produtos hortícolas consiste na redução do peso fresco do produto ao longo do tempo e está diretamente relacionada à movimentação de água no produto após a colheita. Esse intenso processo de transpiração ocasiona um déficit e o produto perde água para o ambiente iniciando um estresse hídrico que tem por características a perda de turgidez e a redução do peso fresco (CHITARRA; CHITARRA, 2005; SANCHES et al., 2017)

Conforme a Figura 1, observa-se que houve aumento progressivo na perda de massa fresca em todos os tratamentos à medida que houve o avanço no período de armazenamento.

Oliveira et al. (2015) e Nascimento et al. (2017) também relataram menor perda de massa fresca em folhas de coentro e alface quando hidroresfriadas em relação ao tratamento controle.

Ainda de acordo com a Figura 1 observa-se que o efeito combinado do hidroresfriamento e o uso de embalagens favoreceram ao longo do tempo de armazenamento as menores perdas de massa nas folhas de jambu. Samira et al. (2011) explica a manutenção da umidade relativa ao redor das folhas em virtude da redução do déficit de pressão de vapor no interior da embalagem, diminuindo a perda de água por transpiração e, consequentemente o murchamento, o que conserva a aparência e o frescor do produto.

Tabela 2: Resumo da análise de variância para as variáveis: perda de massa fresca (PMF), cor da folha (CRFL), escurecimento da folha (EF), odor (ODR), qualidade geral (QG), sólidos solúveis (SS) e acidez titulável (AT) em função das embalagens de armazenamento e dos dias de avaliação

\begin{tabular}{|c|c|c|c|c|c|c|c|c|}
\hline \multirow{2}{*}{ Fontes de variação } & \multicolumn{8}{|c|}{ Quadro de análise } \\
\hline & GL & PMF & CRFL & $\mathrm{EF}$ & ODR & QG & SS & AT \\
\hline Embalagens & 4 & $1743,97 * *$ & $26,03 * *$ & $25,68 * *$ & $46,08 * *$ & $85,00 * *$ & $113,49 * *$ & $40,88 * *$ \\
\hline Dias & 4 & $210,25 * *$ & $34,28 * *$ & $12,63 * *$ & $11,08 * *$ & $21,18 * *$ & $9,25^{* *}$ & $12,21 * *$ \\
\hline Int. Embalagens x Dias & 16 & $20,51 * *$ & $11,40 * *$ & $1,34 \mathrm{~ns}$ & $1,08 \mathrm{~ns}$ & $2,05^{*}$ & $22,24 * *$ & $10,40 * *$ \\
\hline Tratamento & 24 & $339,37 * *$ & $17,65^{* *}$ & $7,27 * *$ & $10,25 * *$ & $19,06 * *$ & $35,28 * *$ & $15,78 * *$ \\
\hline Resíduo & 75 & 0,18 & 0,06 & 1,15 & 0,68 & 0,41 & 0,14 & 0,07 \\
\hline $\mathrm{CV}(\%)=$ & & 2,16 & 0,49 & 5,26 & 3,17 & 2,89 & 2,09 & 0,52 \\
\hline
\end{tabular}


Álvares et al. (2010) também observaram que o uso do hidroresfriamento associado ao acondicionamento em embalagem foi eficiente em conservar os ramos de salsinha durante $\mathrm{o}$ armazenamento refrigerado em relação às amostras somente hidroresfriadas ou sem resfriamento, semelhante ao verificado neste trabalho.

De modo geral os tratamentos hidroresfriamento + PVC e hidroresfriamento + saco de polietileno foram mais eficientes em controlar a perda de água das folhas de jambu com percentuais médios ao final do armazenamento de 6,4 e 5,8\%, respectivamente, não diferindo entre si (Figura 1).

Analisando a Figura 2 é possível observar que até o $3^{\circ}$ dia de armazenamento todas as amostras de jambu apresentavam-se com coloração verde, não diferindo entre si. Nas amostras dos tratamentos testemunha e quando somente hidroresfriadas nota-se perda da coloração verde a partir do $6^{\circ}$ dia de avaliação permanecendo até o último dia de avaliação.

Os resultados desta pesquisa corroboram com os relatos de Borsati et al. (2014), onde a menor perda de massa fresca nas folhas de couve ocorreu quando houve pré-hidratação em solução contendo ácido salicílico e acondicionamento em sacos plásticos de polietileno. Ribeiro et al. (2011) notaram maior conservação das folhas de capuchinha sob atmosfera modificada através do uso do filme de PVC, reduzindo a perda de massa fresca das amostras em relação aos demais biofilmes. Barbosa et al. (2015), avaliando a qualidade póscolheita de folhas de ora-pros-nobis verificaram que somente o uso do hidroresfriamento quando associado ao saco plástico de polietileno forneceu a menor taxa de perda de massa fresca.

De acordo com Streit et al. (2005) a perda da coloração verde deve-se à decomposição estrutural da clorofila em decorrência de vários fatores que atuam isoladamente ou em conjunto. Dentre eles podem ser citadas as transformações no $\mathrm{pH}$, causadas principalmente pelo acúmulo de ácidos orgânicos e outros compostos nos vacúolos, ativação da enzima clorofilase e presença de sistemas oxidantes.

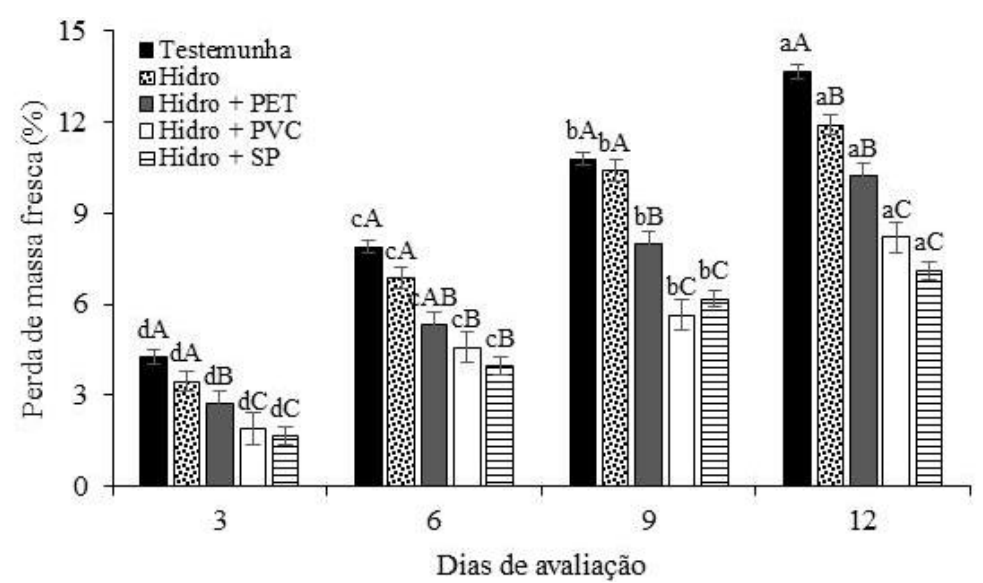

Figura 1: Evolução da perda de massa fresca (\%) nas folhas de jambu em função da embalagem de armazenamento e dos dias de avaliação $10 \pm 2{ }^{\circ} \mathrm{C}$. Letras minúsculas (tempo de armazenamento) e maiúsculas (tratamentos) não diferem entre si pelo teste de Tukey ao nível de $5 \%$ de probabilidade.

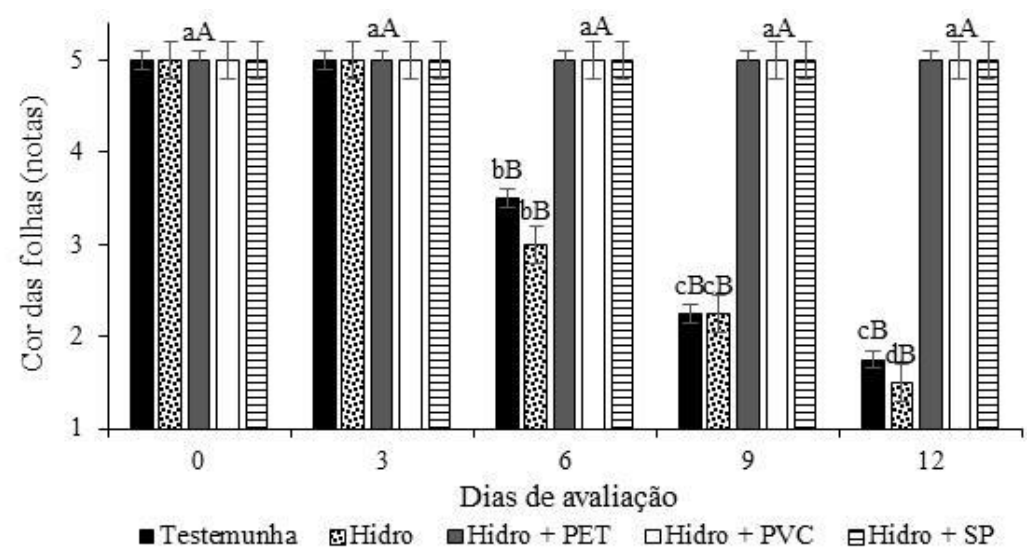

Figura 2: Cor das folhas de jambu em função da embalagem de armazenamento e dos dias de avaliação a $10 \pm 2^{\circ} \mathrm{C}$. Letras minúsculas (tempo de armazenamento) e maiúsculas (tratamentos) não diferem entre si pelo teste de Tukey ao nível de 5\% de probabilidade. 
Analisando a Figura 2 é possível observar que até o $3^{\circ}$ dia de armazenamento todas as amostras de jambu apresentavam-se com coloração verde, não diferindo entre si. Nas amostras dos tratamentos testemunha e quando somente hidroresfriadas nota-se perda da coloração verde a partir do $6^{\circ}$ dia de avaliação permanecendo até o último dia de avaliação.

A combinação do hidroresfriamento com as embalagens mantiveram durante todo o período experimental a cor verde das folhas, não havendo diferenças entre si (Figura 2). É provável que a água absorvida pelas folhas durante o processo de resfriamento e uso das embalagens tenha favorecido uma boa composição em sua atmosfera interna, permitido acúmulo de $\mathrm{CO}_{2}$ e redução do $\mathrm{O}_{2}$, reduzindo assim a produção e a ação do etileno, bem como de enzimas responsáveis pela degradação da clorofila (ÁLVARES; NEGREIROS, 2010). Álvares et al. (2007) e Barbosa et al. (2016) também verificaram menor perda da cor verde em ramos de salsa e de hortelã pimenta, quando estes foram submetidos ao tratamento combinado de resfriamento e embalagem

Em suma, o armazenamento refrigerado das folhas de jambu foi o principal fator para controlar a degradação da clorofila uma vez que a maior nota verificada foi de 2,9 e 2,6 no último dia de avaliação para os tratamentos testemunha e hidroresfriamento, respectivamente, caracterizando-as como de coloração verde-claro à verde amarelado (Figura 2). França et al. (2015) e Oliveira et al. (2015) também atribuíram ao acondicionamento em refrigeração a preservação da clorofila em folhas de alfaces e em ramos e folhas de coentro uma vez que não observaram efeito do hidroresfriamento em relação ao tratamento controle ao longo do tempo de armazenamento.

No que se refere ao escurecimento das folhas, observa-se que o melhor tempo de armazenamento para a conservação das folhas de jambu foi ao tempo zero quando a nota atribuída foi 5 caracterizando as amostras como escurecimento ausente, tal fato já era esperado uma vez que as folhas recém colhidas não apresentavam danos que favorecessem o aparecimento dessas injúrias (Figura 3A).

Para Tsantili et al. (2010) os danos mecânicos gerados nas etapas de processamento acabam por romper as membranas e causam extravasamento de conteúdos celulares que servem de substrato para enzimas antioxidantes, que como consequência, promovem o escurecimento dos tecidos, e, portanto, o aparecimento das manchas escurecidas características da injúria por frio.

Ainda de acordo com a Figura 3A, nota-se que o avanço no tempo de armazenamento aumentou a incidência de escurecimento nas folhas de jambu caracterizando-as com nota 2 (escurecimento severo) ao final de 12 dias. De forma similar, Sanches et al. (2017) também observaram aumento no escurecimento das folhas em cultivares de alfaces minimamente processadas após 12 dias de armazenamento refrigerado.

$\mathrm{O}$ uso do hidroresfriamento de forma isolada e quando combinado com acondicionamento das amostras em diferentes embalagens favoreceu menor ocorrência de escurecimento das folhas em relação ao tratamento controle que foi caracterizado com nota 2 escurecimento severo (Figura 3B). A combinação de hidroresfriamento e as embalagens saco plástico de polietileno e filme de PVC não diferiram entre si e mantiveram as amostras durante doze dias de armazenamento com notas de 3,95 e 3,55 respectivamente, ou seja, escurecimento leve a moderado (Figura 3B).

Para Álvares e Negreiros (2010) a baixa incidência de escurecimento das folhas acondicionadas em embalagens está associada ao acúmulo de água no interior das mesmas possibilitando as trocas metabólicas e a transpiração das folhas durante o armazenamento. Silveira et al. (2014) verificaram que durante o armazenamento de agrião embalado em diferentes materiais houve aumento progressivo dos valores de luminosidade durante 12 dias de armazenamento indicando que não houve escurecimento das folhas em relação às amostras não embaladas cujos valores de luminosidade reduziram indicando perda da coloração característica do produto e aparência mais escura.
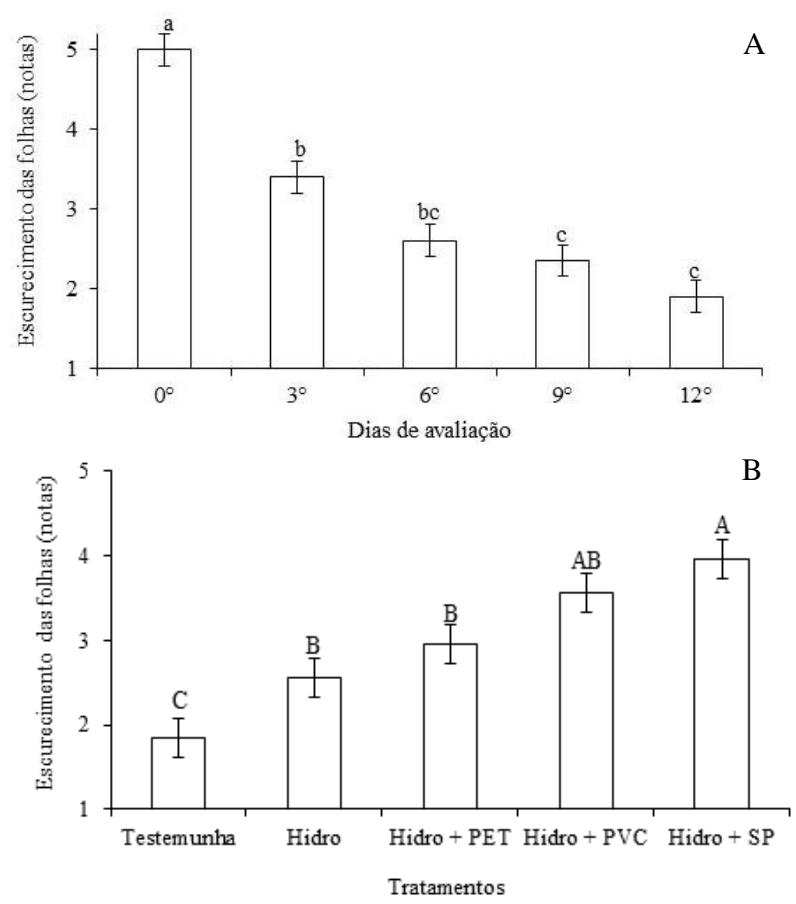

Figura 3: Análise sensorial sobre o escurecimento das folhas de jambu em função dos dias de avaliação (A) e dos tratamentos com hidroresfriamento e embalagens durante armazenamento refrigerado (B) a $10 \pm 2{ }^{\circ} \mathrm{C}$. Letras maiúsculas não diferem entre si pelo teste de Tukey ao nível de $5 \%$ de probabilidade. 
Para a variável odor houve diferença significativa $(\mathrm{p}<0.01)$ somente nos valores isolados (dias e embalagens).

Nota-se que com o tempo de armazenamento houve redução das notas atribuídas indicando a perda do odor característico do jambu fresco (Figura 4A). Segundo Porte e Maia (2001), o mau odor em hortaliças é ocasionado principalmente pela atuação da enzima lipoxigenase, fazendo com que haja a peroxidação enzimática de ácidos graxos insaturados, catalisados por lipoxidases levando a produção de aldeídos e cetonas, responsáveis por alterações bioquímicas de aromas naturais ocasionando a rancidez, perda de sabores e aromas desejáveis nos alimentos.

Ainda de acordo com a Figura 3A nota-se que até o $9^{\circ}$ dia de armazenamento as amostras ainda foram caracterizadas com nota 3,0, isto é, odor moderado. Sabir (2012) também encontrou redução no odor fresco de brócolis com limitação de até 14 dias em refrigeração. Monteiro et al. (2016) ao avaliar folhas de jambu notou odor fresco nas folhas durante 8 dias de armazenamento refrigerado.
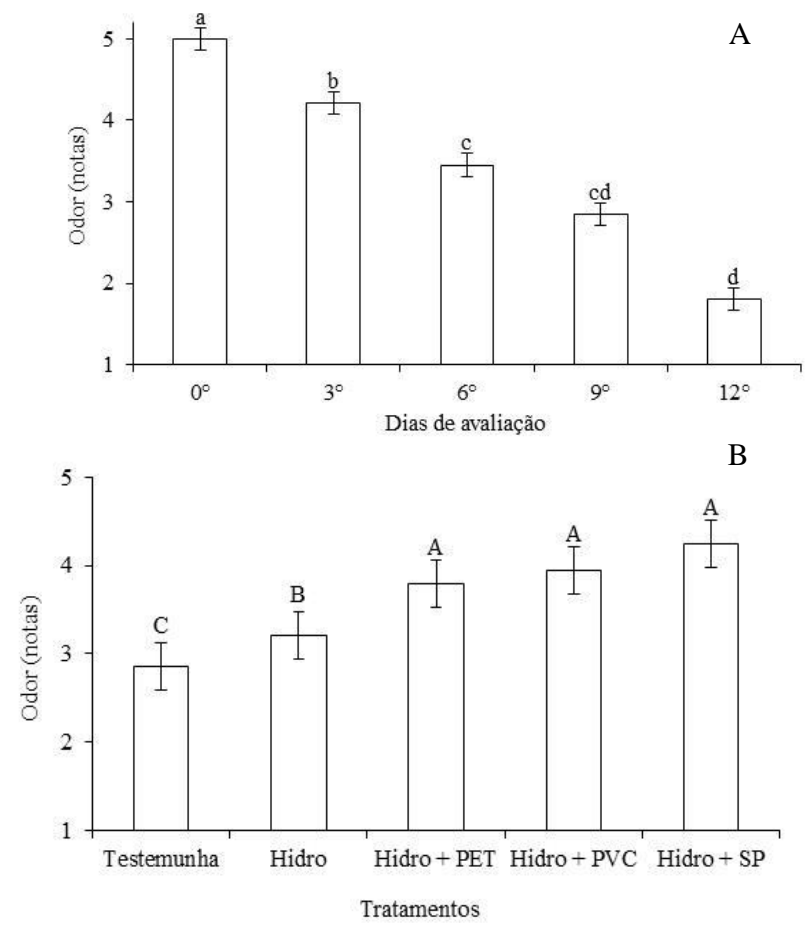

Figura 4: Análise sensorial sobre o odor das folhas de jambu em função dos dias de avaliação (A) e dos tratamentos com hidroresfriamento e embalagens durante armazenamento refrigerado (B) a $10 \pm 2{ }^{\circ} \mathrm{C}$. Letras maiúsculas não diferem entre si pelo teste de Tukey ao nível de $5 \%$ de probabilidade.

Avaliando os tratamentos nota-se que a utilização do hidroresfriamento associado ao acondicionamento das amostras em diferentes embalagens preservou o aroma do jambu; observa-se notas médias de 3,79 (Hidro + PET), 3,94 (Hidro + PVC) e 4,18 (Hidro + SP) sem diferenças entre si (Figura 4B), caracterizando-as como nenhum odor, não típico. O uso do hidroresfriamento de forma isolada mostrou-se superior ao tratamento testemunha com nota média de 3,21 (odor moderado) e 2,85 (odor característico fraco) (Figura 4B).

A qualidade geral das amostras foi afetada com o tempo de armazenamento em todos os tratamentos (Figura 5), tal fato já era esperado uma vez que a qualidade de produtos vegetais após a colheita não pode ser melhorada, apenas mantida por um determinado período. Nas amostras dos tratamentos testemunha e quando somente hidroresfriadas a perda de qualidade é evidenciada $\operatorname{logo}$ no $3^{\circ}$ dia de armazenamento com valores médios de 2,85 e 3,21 , respectivamente, caracterizando-as como 'defeito médio, não limitado para consumo'. Ao final de nove dias as amostras receberam nota 1 caracterizando como 'extremamente pobre, não utilizável' (Figura 5).

A associação dos tratamentos hidroresfriamento e embalagem permitiu maior período de conservação das folhas de jambu, principalmente quando acondicionadas nas embalagens sacos de polietileno e quando recobertas com filme de PVC cujas notas ao final de 12 dias foram de 2,95 e 2,87, respectivamente; valores próximos a 3 (defeito médio, não limitado para consumo). A concentração de sólidos solúveis totais sofreu alterações significativas entre os tratamentos com teores médios oscilando entre o primeiro e o último dia de avaliação entre 2,4 a $5,18^{\circ}$ Brix, respectivamente (Figura 6).

A acidez apresentou variação ao longo do tempo de armazenamento em todos os tratamentos, como pode ser visualizado na Figura 7. Apesar das hortaliças em geral possuírem baixo teor de acidez, esta variável é atribuída principalmente aos ácidos orgânicos que se encontram dissolvidos nos vacúolos das células, seja na forma livre ou combinada com sais, glicosídeos e outros (CHITARRA e CHITARRA, 2005).

Nas amostras dos tratamentos testemunha e quando somente hidroresfriadas nota-se um aumento atingindo valores médios de 0,0275 e $0,0255 \mathrm{~g} / 100 \mathrm{~g}$ ácido oxálico no $6^{\circ}$ dia de avaliação, seguido de regressão até o fim do período de avaliação. Para as amostras dos tratamentos em que houve a combinação do hidroresfriamento com a embalagem o aumento nos teores de acidez permaneceu até o $9^{\circ}$ dia de análise e posterior diminuição no $12^{\circ}$ dia (Figura 7).

Monteiro et al. (2016) ao avaliar folhas de jambu minimamente processadas e armazenadas sob refrigeração notaram redução nos valores de acidez no decorrer do tempo de armazenamento. Sanches et al. (2017) verificaram variações no conteúdo de SST durante o armazenamento de cultivares de alface sob atmosfera modificada. 


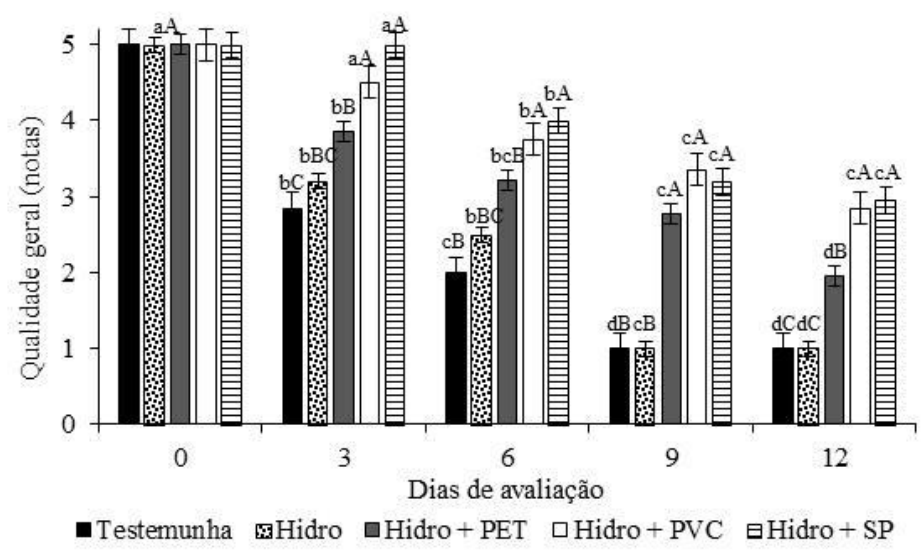

Figura 5: Análise sensorial sobre a qualidade geral das folhas de jambu em função da embalagem de armazenamento e dos dias de avaliação a $10 \pm 2^{\circ} \mathrm{C}$. Letras minúsculas (tempo de armazenamento) e maiúsculas (tratamentos) não diferem entre si pelo teste de Tukey ao nível de $5 \%$ de probabilidade.

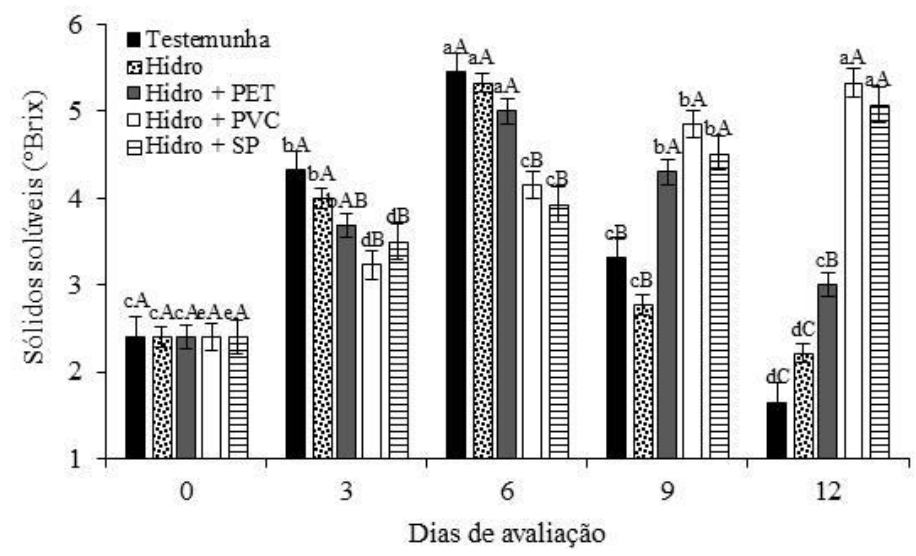

Figura 6: Variação no conteúdo de sólidos solúveis ( ${ }^{\circ}$ Brix) nas folhas de jambu em função da embalagem de armazenamento e dos dias de avaliação a $10 \pm 2{ }^{\circ} \mathrm{C}$. Letras minúsculas (tempo de armazenamento) e maiúsculas (embalagens) não diferem entre si pelo teste de Tukey ao nível de $5 \%$ de probabilidade.

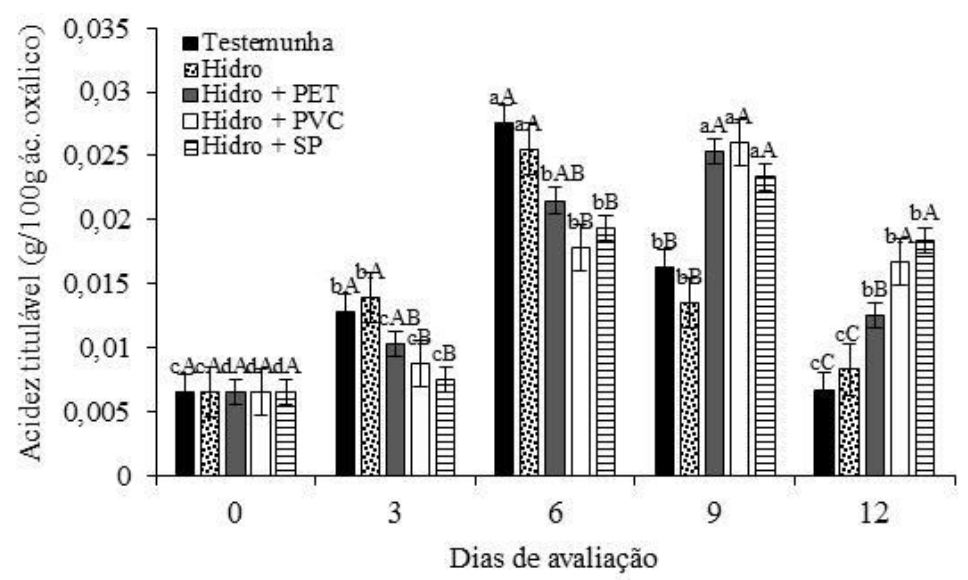

Figura 7: Oscilação nos valores médios sobre a acidez titulável (g.100g ácido oxálico) em folhas de jambu em função da embalagem de armazenamento e dos dias de avaliação a $10 \pm 2{ }^{\circ} \mathrm{C}$. Letras minúsculas (tempo de armazenamento) e maiúsculas (embalagens) não diferem entre si pelo teste de Tukey ao nível de $5 \%$ de probabilidade.

Para Chitarra e Chitarra (2005) essa variação durante o acondicionamento pode estar relacionada aos processos bioquímicos da respiração, que tanto sintetiza quanto consome ácidos orgânicos à medida que o fruto vai chegando ao estádio de senescência; assim quanto menor o teor de acidez maior será o estádio de maturação/senescência.

Possivelmente o aumento da acidez até o sexto dia de armazenamento nas amostras dos tratamentos testemunha e quando somente hidroresfriadas deve-se ao efeito do acondicionamento sob refrigeração 
reduzindo o consumo dos ácidos orgânicos. Mesmo fato pode ser atribuído aos tratamentos em que houve o efeito combinado com as embalagens cuja conservação proporcionou maior conservação em função do baixo consumo dos ácidos orgânicos. Souza et al. (2017) e Nascimento et al. (2017) verificaram que as folhas de coentro e alface quando hidroresfriadas e embaladas apresentaram maior teor de acidez ao longo de 12 dias em relação as amostras não resfriadas e embaladas, indicando maior período de conservação.

\section{Conclusões}

O uso do hidroresfriamento apresentou resultados satisfatórios em relação ao tratamento testemunha sobre as variáveis: odor, SST e escurecimento das folhas e na perda de massa fresca.

$\mathrm{O}$ efeito combinado do hidroresfriamento e embalagens plásticas promoveram maior conservação do jambu para todas as variáveis avaliadas, sobretudo nas embalagens saco plástico de polietileno e PVC.

A utilização da embalagem saco plástico de polietileno é mais indicada pelo potencial de conservação e do preço mais acessível.

\section{Referências Bibliográficas}

ÁlVARES, V. S.; FINGER, F. L.; SANTOS, R. C. A.; NEGREIROS, J. R. S.; CASALI, V. W. D. Effect of précooling on the postharvest of parsley leaves. Journal of Food, Agriculture \& Environment, Helsinki, v. 1, n. 1, p. 31-34, 2007.

ÁLVARES, V S; NEGREIROS, J. R. S. Pré-resfriamento e embalagem na conservação de folhas de salsa. Brazilian Journal of Food Technol. Campinas-SP, v. 13, n. 2, p. $107-$ 1.2010 .

AOAC. ASSOCIATION OF OFFICIAL ANALYTICAL CHEMISTRY. Official methods of analysis of the Association of Official Analytical Chemistry. Washington: AOAC, 2012.

BARBOSA, C. K. R.; FINGER, F. L.; CASALI, V. W. D. Handling and postharvest shelf life of ora-pro-nobis leaves. Acta Scientiarum. Agronomy. Londrina-PR, v. 37, n. 3, p. 307-311, 2015.

BARBOSA, C. K. R. FONSECA, M. C. M. ; SILVA, T. P. ; FINGER, F. L.; CASALI, Vicente Wagner Dias ; CECON, P. R. . Effect of hydrocooling, packaging, and cold storage on the post-harvest quality of peppermint (Mentha piperita L.). Revista Brasileira de Plantas Medicinais, Campinas-SP, v. 18 , n. 1, p. 248-255, 2016.

BORSATI, F. C.; MAZARO, S. M.; DIAS, C. A.; ROCHA, R. C. D. S.; BERTONCELLI, D. J. Salycilic acid application in postharvest cabbage leaves butter. Applied Research \& Agrotechnology. Guarapuava-MG, v. 7, n. 3, p. 25-32, 2014.
CHITARRA, M. I. F.; CHITARRA, A. B. Pós-colheita de frutas e hortaliças: fisiologia e manuseio. 2 ed. Lavras-MG: Editora UFLA, 2005. 785 p.

FRANÇA, C. F. M.; RIBEIRO, W. S.; SILVA, F. C.; COSTA, L. C.; RÊGO, E. R.; FINGER, F. L. Hydrocooling on postharvest conservation of butter lettuce. Horticultura Brasileira. Brasilia-DF, v. 33, n. 3, p. 383-387, 2015.

GUSMÃO, M. T. A.; GUSMÃO, S. A. L. Jambu da Amazônia [Acmella olerácea (L.) R. K. Jansen]: Características gerais, cultivo convencional, orgânico e hidropônico. Belém-PA: Universidade Federal Rural da Amazônia, 2013. 135 p.

LORENZI, H.; MATOS, F. J. A. Plantas Medicinais no Brasil - Nativas e Exóticas. 2. ed. Nova Odessa- SP: Instituto Plantarum, 2008. 512 p.

LUENGO, R. F. A.; CALBO, A. G. Pós- colheita de hortaliças. Brasilia-DF: Embrapa Informação Tecnológica, 2011. 251 p. (Documento 500 perguntas, 500 respostas).

MACHADO, N. P.; COUTINHO, E. F.; CAETANO, E. R. Embalagens plásticas e refrigeração na conservação póscolheita de jabuticaba. Revista Brasileira de Fruticultura, Jaboticabal-SP, v. 29, n. 1, p. 166-168, 2007.

MAPA. MINISTÉRIO DA AGRICULTURA, PECUÁRIA E ABASTECIMENTO. Manual de hortaliças nãoconvencionais. Brasília-DF: MAPA, 2010. 92 p. Disponível em:

http://www.abcsem.com.br/docs/manual_hortalicas_web.pdf. Acesso em: 15 mar. 2017.

MONTEIRO, C. M. O.; SALLES, M. L. O. C.; SILVA, A. E.; PELAIS, A. C. A. Avaliação de sanitizantes na qualidade microbiológica de jambu (Spilantes oleraceae Linn.) minimamente processado. Journal of Fruits and Vegetables, Rio de Janeiro-RJ, v. 1, n. 2, p. 176-179, 2016.

NASCIMENTO, G. A. S.; SANCHES, A. G.; MORIEIRA, E. G. S; CORDEIRO, A. M. C: Tratamento hidrotérmico na conservação e qualidade pós-colheita de alface. Revista Trópica - Ciências Agrárias e Biológicas. Chapadinha-MA, v, 10, n. 1, p. 65-76, 2017.

OLIVEIRA, L. S.; SILVA, T. P.; FERREIRA, A. P. S.; PEREIRA, A. M.; FINGER, F. L. Efeito do hidroresfriamento na conservação pós-colheita de coentro. Horticultura Brasileira. Brasília-DF, v. 33, n. 4, p. 448-452, 2015.

PORTE, A.; MAIA, L. H. Alterações fisiológicas, bioquímicas e microbiológicas de alimentos minimamente processados. Boletim do CEPPA. Curitiba-PR, v.19, n. 2, p. 105-118, 2001

REIS, H. F.; MELO, C. M.; MELO, E. P.; SILVA, R. A.; SCALON, S. P. Q. Conservação pós-colheita de alface crespa, de cultivo orgânico e convencional, sob atmosfera modificada. Horticultura Brasileira. Brasília-DF, v. 32, n. 3, p. 303-309, 2014.

RIBEIRO, W. S.; COSTA, L. C.; ALMEIDA, E. I. B.; BRAGA JUNIOR, J. M.; BRUNO, R. L. A.; BARBOSA, J. A. Conservação e fisiologia pós-colheita de folhas de Capuchinha, utilizando atmosfera modificada em condições 
ambientais e de refrigeração. Horticultura Brasileira, Brasília- DF, v. 29, n. 2, p.73-80, 2011.

RINALDI, M. M.; BENEDETTI, B. C. CALORE, L. Efeito da embalagem e temperatura de armazenamento em repolho minimamente processado. Ciência Tecnologia de Alimentos. Campinas- SP, v. 25, n.3, p. 480-486, 2005.

SABIR, F. K. Postharvest quality response of broccoli florets to combined application of 1-methylcyclopropene and modifield atmosphere packaing. Agricultural and Food Science, Lemu, v. 21, n. 3, p. 421-429, 2012.

SAMIRA, A.; WOLDETSADIK, K.; WORKNEH, T. S. Postharvest quality and shelf life of some hot pepper varieties. Journal of Food Science and Technology, Mysore, USA, v. 50, n. 5 , p. 842-855, 2011.

SANCHES, A. G.; SILVA, M. B.; COSTA, M. J. M.; MOREIRA, E. G. S.; COSME, S. S.; CORDEIRO, C. A. M. Avaliação da qualidade de alfaces minimamente processadas cultivadas em sistema hidropônico. Revista Trópica Ciências Agrárias e Biológicas. Chapadinha-MA, v. 10, n. 1, p. 19-31, 2017.
SILVA, F. A. S.; AZEVEDO, C. A. V. The assistat software version 7.7 and its use in the analysis of experimental data. African Journal of Agricultural Research, Nigéria, v. 11, n. 39, p. 3733-3740, 2016.

SILVEIRA, A. C.; ARANEDA, C.; HINOJOSA, A.; ESCALONA, V. H. Effect of non-conventional modified atmosphere packaging on fresh cut watercress (Nasturtium officinale R. Br.) quality. Postharvest Biology and Technology, Amsterdã, NED, v. 92, n. 3, p.114-120, 2014.

SOUZA, M. A.; SANCHES, A. G.; MOREIRA, E. G. S.; CORDEIRO, C. A. M. Eficiência do hidroresfriamento na conservação e qualidade pós-colheita de coentro (Coriandrum sativum L.). Revista Trópica - Ciências Agrárias e Biológicas, Chapadinha-MA, v. 10, n. 1, p.32-40, 2017.

STREIT, N. M.; CANTERLE, L. P.; CANTO, M. W.; HECKTHEUE, L. H. H. As clorofilas. Ciência Rural. Santa Maria-RS, v. 35, n. 3, p. 748-755, 2005.

TSANTILI, E.; SHINA, Y.; NOCKA, J. F.; WATKINS, C. B. Antioxidant concentrations during chilling injury development in peaches. Postharvest Biology and Technology, Amsterdã, NED, v. 57, n. 2, p. 27-34, 2010. 